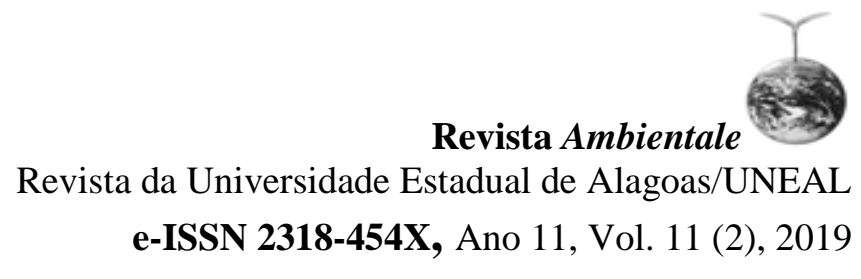

\title{
Crescimento inicial do milho sob aplicação de esterco bovino
}

\section{Initial growth of corn under application of esterco bovino}

\author{
Lucimara Alves GOMES ${ }^{1}$, Francisco de Assis da SILVA $^{2 *}$, Francisco Hevilasio Freire PEREIRA ${ }^{3}$, \\ José Eustáquio Campos JUNIOR ${ }^{4}$, Jackson Silva NOBREGA ${ }^{5}$, Mirandy dos Santos DIAS ${ }^{6}$

\footnotetext{
${ }^{1}$ Engenheira agrônoma pela Universidade Federal de Campina Grande, e-mail

${ }^{2}$ Universidade Federal de Campina Grande, Doutorando em Engenharia Agrícola, e-mail: agrofdsilva@gmail.com

${ }^{3}$ Universidade Federal de Campina Grande, professor Dr. do curso de agronomia, e-mail. fhfperiera@ hotmail.com

${ }^{4}$ Escola de Superior de Agricultura Luiz de Queiroz, Doutorando em Engenharia Agrícola, e-mail:

${ }^{5}$ Universidade Federal da Paraíba, Doutorando em agronomia, e-mail: jacksonobrega@ @otmail.com

${ }^{6}$ Universidade Federal de Campina Grande, Mestrando em Engenharia Agrícola, e-mail: mirandydias@gmail.com
}

E-mail para correspondência: agrofdsilva@gmail.com

Resumo - Objetivou-se avaliar o crescimento inicial de plantas de milho aos 30 dias após a semeadura cultivadas em solo salino sob duas formas de aplicação de esterco bovino. O experimento foi realizado na Universidade Federal de Campina Grande (UFCG), Centro de Ciências e Tecnologia Agroalimentar (CCTA) Pombal-PB, no período de abril a maio de 2015, utilizando o híbrido da variedade de milho AG 1051. O arranjo experimental foi realizado em blocos casualizados em esquema fatorial 4 x 2, correspondente a 4 doses de esterco bovino $(1,3,5 \mathrm{e}$ $7 \%$ da capacidade do recipiente) e duas formas de aplicação (aplicado na camada superficial do solo e incorporação total ao solo), com 4 repetições, totalizando 32 unidades experimentais. O plantio foi realizado em vasos com capacidade de $10 \mathrm{dm}^{3}$ de solos, semeado manualmente quatro sementes por vaso. As avaliações ocorreram aos trinta dias após a semeadura, sendo avaliada a altura de planta (AP), diâmetro do colmo (DC), Número de folhas (NF) e a massa seca de folha, caule e total. Quando comparado as formas de aplicação, as plantas de milho se desenvolveram melhor quando o esterco foi incorporado total ao solo. Foi observado que a dose de $7 \%$ promoveu um maior crescimento e a cúmulo de massa em plantas de milho aos 30 dias após a semeadura.

Palavras-chaves: Zea mays L. Adubação orgânica. Estresse salino.

\begin{abstract}
The objective of this study was to evaluate the initial growth of corn plants grown in saline soil under two forms of bovine manure application. The experiment was carried out at the Federal University of Campina Grande (UFCG), Center for Agro-Food Science and Technology (CCTA) Pombal-PB, from April to May 2015, using the corn variety hybrid AG 1051. The experimental arrangement was (1, 3, 5 and $7 \%$ of the container capacity) and two forms of application (applied to the topsoil and total soil incorporation) were performed in a randomized complete block design in a 4 x 2 factorial scheme, corresponding to 4 doses of bovine manure, with 4 replicates, totaling 32 experimental units. Planting was carried out in pots with a capacity of 10 dm3 of soil, manually seeded four seeds per pot. The evaluations occurred 30 days after sowing, evaluating the plant height (AP), stalk diameter (DC), number of leaves (NF) and dry mass of leaf, stem and total. When compared to the application forms, maize plants developed better when
\end{abstract}




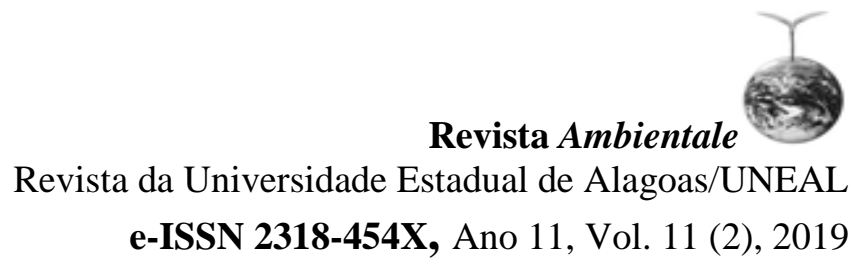

manure was fully incorporated into the soil. It was observed that the $7 \%$ dose promoted greater growth and mass accumulation in maize plants at 30 days after sowing.

Keywords: Zea mays L. Organic Fertilization. Saline Stress.

\section{Introdução}

O milho (Zea mays L.) vem sendo utilizado na América Latina desde os tempos mais remotos, como a principal e tradicional fonte alimentar, ocupando uma posição de destaque entre os cereais mais cultivados no mundo. No Brasil, o milho tem ampla diversidade de uso, sendo que $15 \%$ da produção é utilizada para consumo humano (FARIAS, 2013, p. 22).

A produtividade de milho na safra de 2016/2017 foi de aproximadamente $5.562 \mathrm{~kg}$ ha- 1 resultando em uma produção de 97.842,8 mil toneladas de grãos (CONAB 2018, p.132). No Brasil apesar de se ter uma expansão de apenas 3,86 de área cultivada, nas últimas décadas a produção brasileira de milho vem aumentando em torno de 4,61 vezes. Em face do aumento da população mundial, a previsão é que a produção desse cereal continue crescendo cada vez mais (GALVÃO et al., 2014, p. 820; GERLAND et al. 2014, p.235).

Atualmente a cadeia produtiva da cultura do milho é caracterizada pelas diversas formas de sua utilização, que vai desde a alimentação animal até a indústria de alta tecnologia. Na realidade, o uso do milho em grão como alimentação animal representa a maior parte do consumo desse cereal, isto é, cerca de $70 \%$ no mundo. O Brasil tem se destacado como terceiro maior produtor de grãos, ficando atrás apenas dos Estados Unidos e da China (MIRANDA et al., 2012).

A cultura do milho é cultivada em praticamente todo o território brasileiro, sendo que cerca de $92 \%$ da produção está concentrada nas regiões Sul $(32,2 \%)$, Sudeste $(17,7 \%)$ e Centro-Oeste $(41,7 \%)$. Porém, observa-se que a média de produtividade de milho no Brasil, quando comparada à obtida pelos grandes produtores mundiais, reflete um menor nível tecnológico, isso decorre ao fato que as médias são obtidas em diferentes regiões, em lavouras com diferentes sistemas de cultivos e finalidades de produção, e devido principalmente ao cultivo de safrinha (MIRANDA et al., 2012).

Para se obter uma boa produtividade é necessário um aporte de nutrientes no solo que garantam as plantas o atendimento de suas necessidades. Os resíduos orgânicos utilizados como adubos suprem as plantas com os elementos nutritivos essenciais. A adubação orgânica quando fornecida em doses adequadas possibilita alta produtividade e garante estabilidade da cultura, proporciona melhor eficiência de absorção de nutrientes, contribui para a capacidade de restauração do solo sendo reflexo direto na produção final esperada (CANCELLIER et al., 2010, p. 31).

O esterco apresenta interações benéficas com microrganismos do solo, diminui a sua densidade aparente, melhora a sua estrutura e a estabilidade de seus agregados, aumenta a capacidade de infiltração de água, a aeração e melhora a possibilidade de penetração radicular (ANDREOLA et al., 2000, p.871).

Além disso, a incorporação de compostos orgânicos ao solo aumenta sua capacidade de troca catiônica e sua porosidade, proporcionando melhoria na sua estrutura física e química. $\mathrm{O}$ uso de compostos orgânicos tende a aumentar a vida útil do solo e a não empobrecê-lo, como acontece quando se utilizam apenas os adubos químicos minerais ao longo de anos de cultivo. Promove também, uma diminuição dos riscos de erosão, favorece um bom condicionamento nutricional da 


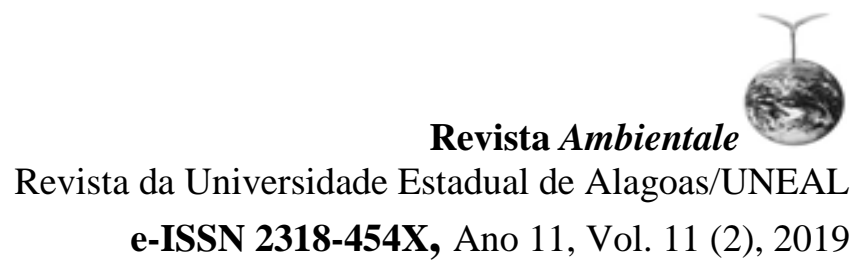

planta e aumenta a produtividade da cultura, sem ocasionar efeitos adversos ao meio ambiente (CORREIA E MORAIS, 2006, p.30).

Segundo Freire e Freire (2007), condicionadores orgânicos (esterco de curral, casca de arroz e vinhaça) também podem contribuir na redução da percentagem de sódio trocável (PST) devido, possivelmente à liberação de $\mathrm{CO}_{2} \mathrm{e}$ ácidos orgânicos durante a decomposição da matéria orgânica, além de atuarem como fontes de cálcio e magnésio, em detrimento do sódio.

Desta forma, objetivou-se avaliar o crescimento inicial de plantas de milho aos 30 dias após a semeadura cultivadas em solo salino sob duas formas de aplicação de esterco bovino.

\section{Material e Métodos}

O experimento foi conduzido em condições de lisimetro na Universidade Federal de Campina Grande, Campus Pombal, no período de abril a maio de 2015. O município está localizado geograficamente $06^{\circ} 52^{\prime} 31^{\prime \prime} \mathrm{S}, 37^{\circ} 49^{\prime} 43^{\prime \prime} \mathrm{W}$ com altitude de $184 \mathrm{~m}$. O clima de Pombal, baseado no sistema de classificação internacional de Köppen, foi incluído no tipo Bsh do tipo quente e seco com chuvas de verão e outono com uma precipitação média de $800 \mathrm{~mm}$ ano.

$\mathrm{O}$ arranjo experimental foi realizado em blocos casualizados em esquema fatorial do tipo $4 \mathrm{x}$ 2, correspondendo a quatro porcentagens de esterco bovino (1, 3, 5 e 7\%) e duas formas de aplicação (incorporação superficial ao solo e incorporação total ao solo) aplicados antes da semeadura, com 10 tratamentos e quatro repetições, totalizando 32 parcelas experimentais.

O cultivo foi realizado em vasos com capacidade de $10 \mathrm{dm}^{3}$, semeando manualmente quatro sementes de milho da cultivar AG 1051 por vaso. Os vasos foram preenchidos com solo classificado como um vertissolos, textura argilosa, cujos resultados médios das análises químicas do solo e do foram: Solo: $\mathrm{P}=149,1 ; \mathrm{K}^{2+}=319,2 ; \mathrm{Na}^{2+}=284,1 \mathrm{mg} \mathrm{dm}{ }^{-3} ; \mathrm{Ca}^{2+}=39,9 \mathrm{mg} \mathrm{dm}{ }^{-3} ; \mathrm{Mg}^{2+}=8,9$; $\mathrm{Al}^{3+}=0,00 ; \mathrm{H}^{+} \mathrm{Al}=0,00 ; \mathrm{SB}=50,85 ; \mathrm{CTC}=50,85 \mathrm{Cmol} \mathrm{dm}^{-3} ; \mathrm{V}=100 ; \mathrm{m}=0 ; \mathrm{PST}=2 \% ; \mathrm{CE}=0,93$ $\mathrm{dS} \mathrm{m}{ }^{-1} ; \mathrm{M} . \mathrm{O}=8,23 \mathrm{~g} \mathrm{~kg}^{-1} ; \mathrm{pH}=7,52$. Esterco: $\mathrm{N}=13,39 \mathrm{~g} \mathrm{~kg}^{-1} ; \mathrm{P}=9,88 \mathrm{~g} \mathrm{~kg}^{-1} \mathrm{e} \mathrm{K}=14,65 \mathrm{~g} \mathrm{~kg}^{-1}$.

Durante a condução do ensaio a média diária das variáveis climáticas para temperatura do ar teve mínima de 31,3 e máxima de $32,8{ }^{\circ} \mathrm{C}$, quanto a umidade relativa do ar ficou entre 42,1 de mínima a 49,9\% máxima.

A semeadura foi realizada diretamente em vasos dispostos no espaçamento de $0,5 \times 0,5 \mathrm{~m}$ com uma profundidade de $2,0 \mathrm{~cm}$, colocando-se quatro sementes de milho com intuito de avaliar inicialmente a emergência. No quinto dia após a semeadura (DAS) foi observada emergência acima de $80 \%$ das plantas. No oitavo DAS foi realizado o desbaste deixando duas plantas por vaso.

As irrigações foram realizadas diariamente parceladas em duas vezes ao dia (8:00 e 17:00h) de forma manual utilizando o método de lisimetria. A quantidade de água aplicada no decorrer do experimento variou de 0,5 a 2,0 L por dia em cada vaso, totalizando uma quantidade de 46 litros de água por vaso durante os 30 dias.

Para monitoração dos aspectos morfológicos da cultura, foi realizada a análise de crescimento e acumulo de massa aos 30 DAS, medindo a altura de planta (AP) pela distância entre o solo e o ápice da planta, diâmetro do colmo (DC) através de um paquímetro digital no colo da planta, e pelo número de folhas por planta (NF) a partir da contagem de folhas madura. Após a análise de crescimento a plantas foram coletadas separando o colmo das folhas e acondicionados em estufa de circulação forçada de ar a $65{ }^{\circ} \mathrm{C}$ por um período de 72 horas. Após a secagem o material 


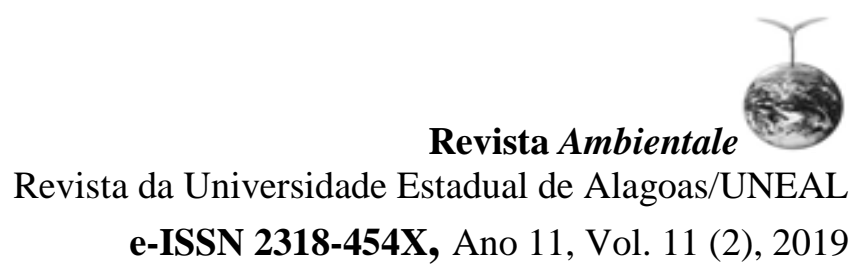

foi pesado em balança analítica e determinado a massa seca do colmo (MSC) (g), massa seca de folhas (MSF) (g) e massa seca total (MST) (g) através da relação MSC e MSF.

Os dados foram submetidos à análise de variância pelo software SISVAR (FERREIRA 2011) e em seguida realizado a regressão para o fator quantitativo (doses) e teste de comparação de médias para o fator qualitativo (formas de aplicação) utilizando (Tukey) ao nível de 5\% de probabilidade.

\section{Resultados e Discussão}

Avaliando as variáveis de crescimentos nas plantas de milho, não foi observada interação significativa entre as doses (D) de esterco bovino e formas de aplicação (A). No entanto, quando estudado os fatores isolados observou-se influencia $(\mathrm{P}<0,05)$ das doses $(\mathrm{D})$ de esterco bovino nas variáveis analisadas: altura de planta (AP), massa seca de folha (MSF), massa seca de caule (MSC) e massa seca total (MST). Para as formas de aplicação foi observado efeito significativo para maioria das variáveis, exceto para altura de planta e número de folhas (Tabela 1).

Tabela 1 - Resumo da análise de variância para altura de planta (AP), diâmetro do colmo (DC), número de folhas (MSF), massa seca de folhas, massa seca do colmo (MSC) e massa seca total (MST) de planta de milho cultivado com esterco bovino em diferentes formas de incorporação

\begin{tabular}{ccccccc}
\hline Fonte de & \multicolumn{5}{c}{ Quadrados médios } \\
\cline { 2 - 7 } variação & $\mathbf{A P}$ & $\mathbf{D C}$ & $\mathbf{N F}$ & $\mathbf{M S F}$ & MSC & MST \\
\hline Doses (D) & $672,8^{*}$ & $39,66^{\mathrm{ns}}$ & $2,87^{\mathrm{ns}}$ & $87,20^{* *}$ & $45,44^{* *}$ & $250,6^{* *}$ \\
Reg. Linear & $1131,56^{* *}$ & $107,32^{*}$ & $6,40^{*}$ & $261,5^{* *}$ & $119,37^{* *}$ & $733,89^{* *}$ \\
Reg. Quad & $524,07^{*}$ & $9,50^{\mathrm{ns}}$ & $2,00^{\mathrm{ns}}$ & $0,006^{\mathrm{ns}}$ & $16,53^{\mathrm{ns}}$ & $17,36^{\mathrm{ns}}$ \\
Aplicação (A) & $67,57^{\mathrm{ns}}$ & $178,13^{* *}$ & $0,12^{\mathrm{ns}}$ & $56,89^{* *}$ & $42,92^{*}$ & $198,1^{* *}$ \\
D x A & $175,38^{\mathrm{ns}}$ & $20,12^{\mathrm{ns}}$ & $1,20^{\mathrm{ns}}$ & $1,09^{\mathrm{ns}}$ & $3,62^{\mathrm{ns}}$ & $5,90^{\mathrm{ns}}$ \\
Resíduo & 77,77 & 14,61 & 1,06 & 5,28 & 7,07 & 20,26 \\
\hline Média & 45,37 & 22,2 & 9,43 & 6,95 & 4,67 & 11,6 \\
CV (\%) & 19,4 & 17,2 & 10,09 & 33,07 & 56,9 & 38,7 \\
\hline ns & &
\end{tabular}

${ }^{\mathrm{ns}}$ não significativo, * significativo a $5 \%$ e ** significativo a $1 \%$ de probabilidade pelo teste $\mathrm{F}$

Para as variáveis altura de planta, massa seca de folha, massa seca de caule e massa seca total, observou-se um comportamento linear crescente a medida que foi aumentado as doses de esterco bovino, o que implica dizer que quando utilizado a dose de $7 \%$ da capacidade do vaso foi a que obteve resultados mais expressivos. Para essas variáveis constatou-se um incremento unitário de 2,71 cm, 1,10, 0,75 e 1,85 g para AP, MSF, MSC e MST, que corresponde ao incremento de $18,97 \mathrm{~cm}, 7,71,5,28$ e 12,9 g respectivamente ao comparar a maior dose (7\%) e a menor dose estudada. Observa-se ainda que o $\mathrm{R}^{2}$ foi bem próximo de 1 , demostrando portanto uma aproximação dos pontos médios estudados (Figura $1 \mathrm{~B}, \mathrm{C}$ e D).

A rápida resposta de crescimento inicial das plantas de milho pode estar associada a baixa relação de $\mathrm{C} / \mathrm{N}$ do esterco, desta forma fornecendo de maneira rápida os nutrientes necessários para o crescimento das plantas, sobretudo a disponibilidade de assimilação do nitrogênio 
Figura 1: Altura de planta (AP), massa seca de folha (MSF), massa seca do colmo (MSC) e massa seca total (MST) de plantas de milho em função da aplicação de diferentes doses de esterco bovino, avaliado aos 30 DAS.

A

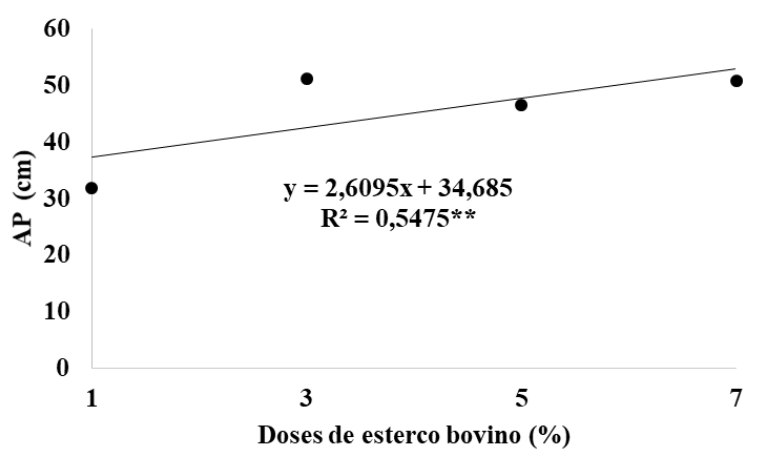

$\mathrm{C}$

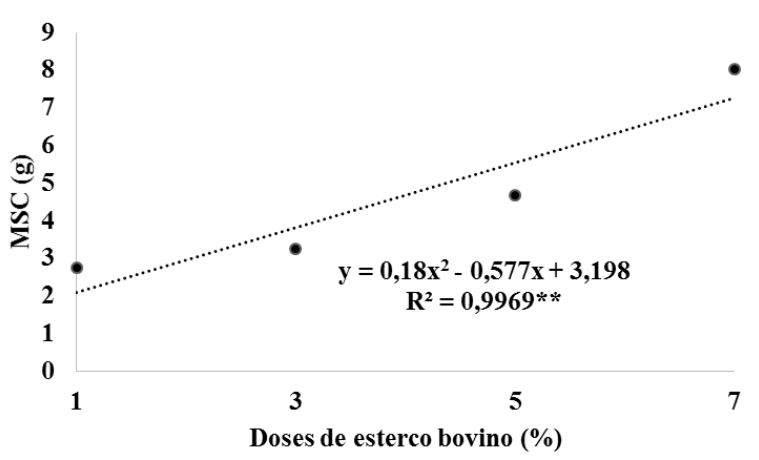

$\mathrm{B}$

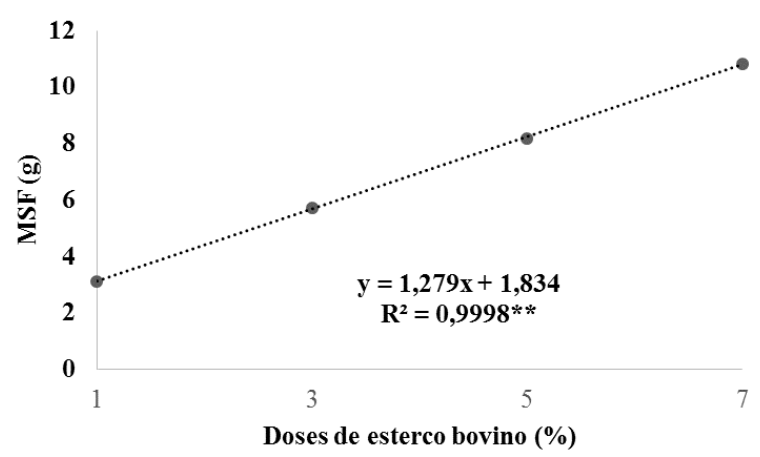

$\mathrm{D}$

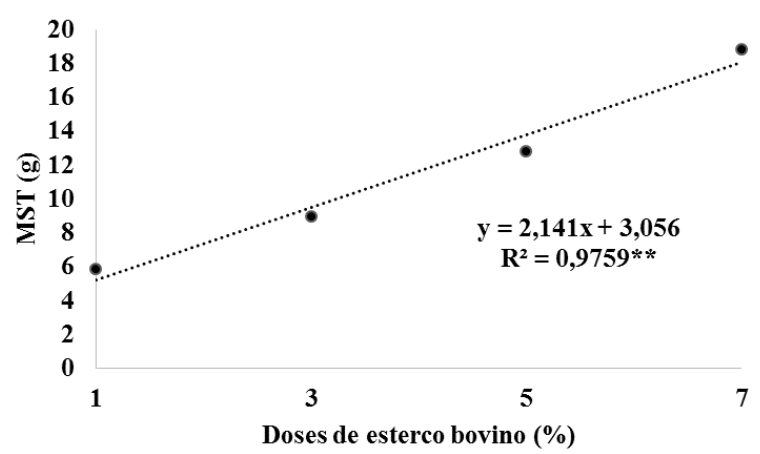

Esse incremento no crescimento e acúmulo de massa seca das plantas de milho, em resposta a aplicação de doses crescentes de esterco bovino está diretamente relacionada ao fornecimento de nutrientes para as plantas, haja vista que a adição de matéria orgânica ao solo tende a contribui para a elevação da capacidade de trocas catiônicas (CTC) do solo e fornece micronutrientes (ZANDONADI et al, 2014, p.15). Desta forma favorecendo uma maior e melhor aproveitamento dos nutrientes por parte dos vegetais (SOUZA et al, 2017, p.242).

De acordo com Zanine e Ferreira (2015, p.890) o uso de esterco como um adubo é uma pratica de adubação viável, pois esta funciona de forma eficiente dando suprimento nutricional as plantas além de ser uma prática que gera menos danos ao ambiente. Porém, necessita-se de mais pesquisas relacionadas ao tema para se determinar doses adequadas para as culturas de interesse agronômico.

Mata et al. (2010) ao verificarem o desenvolvimento do milho híbrido sob diferentes níveis de adubação de esterco bovino, inferiram que a adubação orgânica influenciou significativamente na altura de planta e diâmetro do colmo e que a aplicação do esterco bovino pode substituir a adubação química, sem comprometer o desempenho da cultura. Silva et al. (2008, p.355) e Campos et al. (2009, p. 46) ao estudarem o desenvolvimento de plantas de goiabeira e mamoneira em solo 


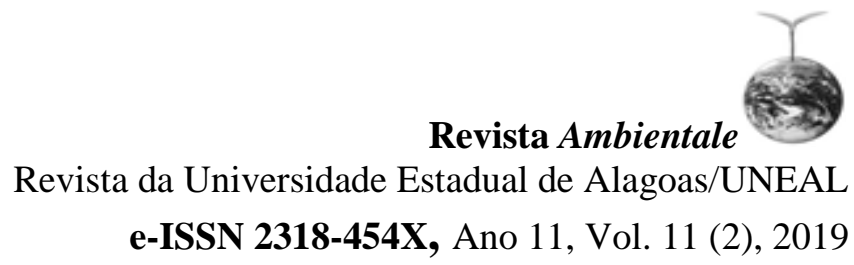

salino com adição de esterco bovino, obtiveram respostas positivas para o crescimento destas culturas.

Desta forma, infere-se que o esterco bovino quando aplicado na quantidade correta pode ser um bom atenuante da salinidade do solo, melhorando as propriedades físicas e químicas do mesmo e consequentemente ajudando no desenvolvimento das plantas cultivadas.

O colmo por sua vez não possui apenas função de suporte de folhas e inflorescências, mas principalmente, atua como uma estrutura destinada ao armazenamento de sólidos solúveis que são utilizados posteriormente na formação dos grãos com isso, plantas com maiores diâmetros de colmo no desenvolvimento inicial, tendem a se tornar plantas mais vigorosas e produtivas (BRITO et al, 2014, p.245). Assim, Medeiros et al. (2010, p. 1413) ao estudar o desenvolvimento do pinhão manso verificaram o efeito da adubação orgânica sobre o número de folha, onde o esterco bovino veio a proporcionar melhores resultados.

Pela tendência dos resultados mostrados na Figura 1 e considerando que o milho é moderadamente sensível a salinidade, apresentando uma salinidade limiar do solo de $1,7 \mathrm{dS} \mathrm{m}^{-1}$ (AYERS E WESTCOT, 1999, p. 153), percebe que o esterco bovino inibiu a intensidade do efeito salino nas plantas. Essa Ação de inibição dos sais através dos insumos orgânicos está associada aos ácidos orgânicos que no interior dos tecidos vegetais reduz o potencial osmótico em relação à solução do solo possibilitando a absorção de água e nutrientes sob condições de estresse salino (BAALOUSHA et al., 2006, p.49).

Sabe-se que a adição de fontes de matéria orgânica ao solo contribui não só para o fornecimento de nutrientes, mas também para melhoria das características físicas do meio de cultivo, assim, o uso de matéria orgânica de forma equilibrada é de fundamental importância para o pleno desenvolvimento das plantas (OLIVEIRA et al., 2009, p. 207).

De acordo Reina et al. (2010, p. 163) o uso de esterco bovino pode ser recomendado tanto para agricultores familiares como para grandes produtores, desde que se tenha uma boa disponibilidade deste insumo, como também mão de obra para sua aplicação. Desta forma, a utilização de estercos na adubação pode aumentar a estabilidade dos sistemas de produção existentes e maximizar a eficiência dos mesmos, reduzindo assim os custos e melhorando a produtividade.

O aumento da matéria seca crescente nas condições do estudo realizado demonstra que com o aumento da aplicação de esterco bovino, a planta se desenvolveu melhor, ou seja, o esterco age de forma eficiente na promoção de reservas na cultura do milho.

Na tabela 2 encontra-se a valores das variáveis de crescimento quando as plantas foram submetidas a aplicação do esterco de forma superficial e incorporado totalmente ao solo.

Tabela 2 - Altura de planta (AP), diâmetro do colmo (DC), número de folhas (NF), massa seca de folha (MSF), massa seca do colmo (MSC) e massa seca total (MST) de plantas de milho em função de duas formas de aplicação de esterco bovino, avaliado aos 30 DAS

\begin{tabular}{lcccccc}
\hline \multirow{2}{*}{ Aplicação do esterco } & $\mathbf{7}$ & \multicolumn{7}{c}{ Médias } \\
\cline { 2 - 7 } & AP & DC & NF & MSF & MSC & MST \\
\hline Superficial ao solo & $43,9 \mathrm{a}$ & $19,6 \mathrm{~b}$ & $5,6 \mathrm{~b}$ & $9,3 \mathrm{a}$ & $3,5 \mathrm{~b}$ & $9,1 \mathrm{~b}$ \\
Incorporado ao solo & $46,8 \mathrm{a}$ & $24,5 \mathrm{a}$ & $8,2 \mathrm{a}$ & $9,5 \mathrm{a}$ & $5,8 \mathrm{a}$ & $14,1 \mathrm{a}$ \\
\hline Média & 45,3 & 22,2 & 9,4 & 6,9 & 4,6 & 11,6 \\
CV\% & 19,44 & 17,2 & 10,9 & 33 & 56 & 38,7 \\
\hline
\end{tabular}

Médias seguidas pela mesma letra na coluna não diferem entre si pelo teste de Tukey ao nível de 5\% de probabilidade. 


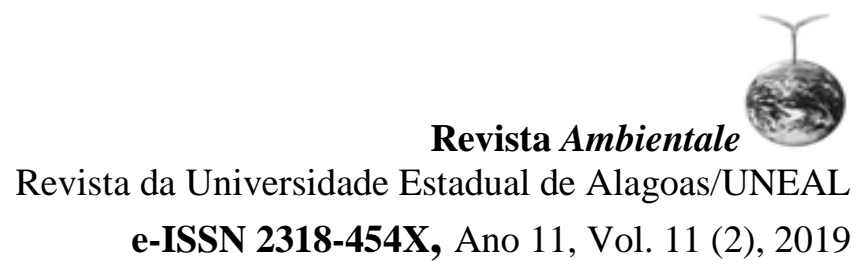

As variáveis de DC, MSF e MST, apresentaram as maiores médias quando tratadas com esterco incorporado do que quando submetidas ao esterco superficial, sendo o tratamento com esterco incorporado a melhor forma de aplicação (Tabela 2). Isso se deve aos benefícios que a incorporação de matéria orgânica ocasiona ao solo, melhorando suas estruturas químicas, físicas e biológicas, proporcionando uma forma de absorção e retenção de nutrientes essenciais a planta, além de melhorar a capacidade de armazenamento de água, favorecendo a aração e drenagem, diminuindo o efeito da erosão, ocasionando elevação da CTC (capacidade de troca catiônica) do solo; melhora as condições do sistema radicular; aumenta o número de microrganismos úteis ao solo, essenciais no controle de pragas e doenças; traz benefício por mais tempo ao solo, pois fornecem lentamente nutrientes, prolongando os efeitos da adubação, entre outros benefícios.

De acordo com (Noronha 2000, p.76; Filgueira, 2008, p. 402; Tejada et al., 2008, p. 1758), dentre os insumos orgânicos, o esterco bovino é a fonte mais utilizada em solos pobres de matéria orgânica, isso porque ele atua como poderoso agente beneficiador do solo, capaz de melhorar substancialmente muitas de suas características físicas e químicas por meio da redução da densidade aparente, melhora na permeabilidade, infiltração e retenção de água, minimização do fendilhamento de solos argilosos, variação de temperatura dos solos, proporciona acúmulo de nitrogênio orgânico, auxilia no aumento do seu potencial de mineralização, disponibilidade de nutriente para as plantas acarretando na qualidade do produto final, onde sua incorporação tem demonstrado um incremento na produtividade e reduzindo o uso de fertilizantes.

O esterco bovino é considerado uma importante fonte orgânica de nutrientes, tendo o fósforo e o potássio rapidamente disponível e o $\mathrm{N}$ fica na dependência da facilidade de degradação dos compostos.

\section{Conclusões}

A aplicação de matéria orgânica através do esterco bovino na proporção de $7 \%$ reflete positivamente nas características de crescimento inicial da cultura do milho e em especial o acúmulo de massa seca da planta aos 30 dias após a semeadura.

\section{Conflito de Interesse}

Os autores não declararam conflito de interesse para esse manuscrito. 


\section{Referências}

ANDREOLA, F.; COSTA, L. M.; OLSZEVSKI, N.; JUCKSCH, I. A cobertura vegetal de inverno e a adubação orgânica e, ou, mineral influenciando a sucessão feijão/milho. Revista Brasileira de Ciência do Solo, Viçosa, v. 24, n. 4, p. 867-874. 2000.

AYERS, R. S.; WESTCOT, D. W. A qualidade da água na agricultura. 2.ed. Campina Grande: UFPB, Estudos FAO 29. Irrigação e Drenagem. 1999.153p.

BAALOUSHA, M.; HEINO, M.M.; LE COUSTUMER, B.K. Conformation and size of humic substances: effects of major cation concentration and type, $\mathrm{pH}$, salinity and residence time. Colloids and surfaces. Physico chemical and engineering aspects, v. 222, n.1-2, 2006. p.48-55,

BRITO, C. F. B.; FONSECA, V. A.; BEBÉ, F. V.; SANTOS, L. G. Desenvolvimento inicial do milho submetido a doses de esterco bovino. Revista Verde, Mossoró, v 9, n. 3, p. 244 - 250, 2014.

CAMPOS, V. B. et al. Crescimento inicial da mamoneira em resposta à salinidade biofertilizante bovino. Revista Magistra, Bahia, v. 21, n. 01, p. 41-47, 2009.

CANCELLIER, L. L.; AFFÉRRI, F. S.; ADORIAN, G. C.; RODRIGUES, H. V. M. Influência da adubação orgânica na linha de semeadura na emergência e produção forrageira de milho. Revista Verde de Agroecologia e desenvolvimento sustentável, Mossoró - RN, v.5, n.5. 25 - 32. 2010.

CONAB - Companhia Nacional de Abastecimento. Acompanhamento da safra brasileira de grãos: v.5 - Safra 2017/18, n.4, $4^{\circ}$ levantamento. Brasília, 2018.132p.

CORREIA, R. M. A.; MORAIS, O. M. Manual de compostagem: processo simplificado. Brasília: Universidade de Brasília, Departamento de Engenharia Florestal, 2006. 36 p.

FARIAS, L; L; P. Avaliação agronômica de híbridos de milho (Zea mays.L) para produção de silagem ou grãos cultivados no Distrito Federal - Universidade de Brasília - Faculdade de agronomia e medicina veterinária, Brasília - DF, 2013. 22 p.

FILGUEIRA, F. A. R. Manual de olericultura: Agrotecnologia moderna na produção e comercialização de hortaliças. Viçosa, MG: UFV, 2008. 402 p.

FREIRE, M. B. G. S.; FREIRE, F. J. Fertilidade do solo e seu manejo em solos afetados por sais. In: NOVAIS, R. F.; ALVAREZ V., V. H.; BARROS, N. F.; FONTES, R. L. F.; CANTARUTTI, R. B.; NEVES, J. C. L. (ed.). Fertilidade do solo. Viçosa: SBCS, p.929-954. 2007.

GALVÃO, J.C.C.; MIRANDA, G.V.; TROGELLO, E.; FRITSCHE-NETO, R. Sete décadas de evolução do sistema produtivo da cultura do milho. Revista Ceres, v.61, suplemento, p.819-828, 2014. 
GERLAND, P.; RAFTERY, A.E.; SEVCIKOVA, H.; KI, N.; GU, D.; SPOORENBERG, T.; ALKEMA, L.; FOSDICK, B.K.; CHUNN, J.; LALIC, N.; BAY, G.; BUETTNER, T.; HEILIG, G.K.; WILMOTH, J. World population stabilization unlikely this century. Science, v.346, n.6206, p.234-237, 2014.

MATA, J. F.; SILVA, J. C. da ; RIBEIRO, J. F.; AFFÉRRI, F. S.; VIEIRA, L. M. Produção de milho híbrido sob doses de esterco bovino. Pesquisa Aplicada \& Agrotecnologia v. 3 no 3 set. Dezembro/2010.

MEDEIROS, K. A. A. de L.; SOFIATTI, V.; SILVA, H.; LIMA, R.; LUCENA, M. A. de; VASCONCELOS, G. C.; ARRIEL, N H. C. Mudas de pinhão manso (jatrophacurcas L.) produzidas em diferentes fontes e doses de matéria orgânica. IV Congresso Brasileiro de Mamona e I Simpósio Internacional de Oleaginosas Energéticas, Anais. João Pessoa, PB - 2010. p. 1413.

MIRANDA, A. R.; DUARTE, J. O.; GARCIA, J. C. Sistema de produção - Cultivo do milho. Sete Lagoas. Embrapa Milho e Sorgo. $8^{\mathrm{a}}$ edição Out./2012. Disponível em:<http://www.cnpms.embrapa.br/publicacoes/milho_8_ed/economia.htm. Acesso em: 21 mar. 2019.

NORONHA, M. A. S. Níveis de água disponível e doses de esterco bovino sobre o rendimento e qualidade do feijão-vagem. Areia: Universidade Federal da Paraíba, 2000. 76p. Dissertação Mestrado.

OLIVEIRA, F. A; OLIVEIRA FILHO, A. F; MEDEIROS, J.F; ALMEIDA JUNIOR, A. B ; LINHARES, P. C. F. Desenvolvimento inicial da mamoneira sob diferentes fontes de matéria orgânica. Revista Caatinga. Mossosró, v. 22, n. 1, p. 206-2011. 2009.

REINA, E.; AFFÉRRI, F. S.; CARVALHO, E. V.; DOTT, M. A.; PELUZIO, J. M. Efeito de doses de esterco bovino na linha de semeadura na produtividade de milho. Revista Verde de agroecologia e desenvolvimento sustentável, v. 5, n. 5, p. 158-164, dez, 2010.

SILVA, A. B. F. et al. Growth and yield of guava irrigated with saline water and addition of farmyard manure. Revista Brasileira de Ciências Agrárias, Recife, v. 03, n. 04, p. 354-359, 2008.

SILVA, F. de A. S. e.; AZEVEDO, C. A. V. de. The Assistat Software Version 7.7 and its use in the analysis of experimental data. Afr. J. Agric. Res, v. 11, n. 39, p. 3733-3740, 2016.

SOUZA, F. M; LIMA, E. C. S; SÁ, F. V. S; SOUTO, L. S; ARAÚJO, J. E. S; PAIVA, E. P. Crescimento inicial do milho sob doses de esterco caprino e disponibilidade de água no solo. Revista Verde de Agroecologia e Desenvolvimento Sustentável, v.12, n. 2, p.241-245, 2017.

TEJADA, M.; GONZALEZ, J. L.; GARCÍA-MARTÍNEZ, A. M. et al. Effects of different green manures on soil biological properties and maize yield. Bioresource Technology, v. 99, 2008. p.1758-1767. 
ZANDONADI, D. B.; SANTOS, M. P.; MEDICI, L. O.; SILVA, J. Ação da matéria orgânica e suas frações sobre a fisiologia de hortaliças. Horticultura Brasileira, v.32, n.1, p.14-20, 2014.

ZANINE, A. M.; FERREIRA, D. J. Animal Manure as am Nitrogen Source to Grass. American Journal of Plant Sciences, v.6, n.7, p.899-910, 2015. 